\title{
Cultura política de la juventud urbana de la región metropolitana de Managua
}

\author{
Hloreley Osorio Mercado* y Luis Serra Vásquez**
}

\section{Recibido: julio de 2011 / Aceptado: octubre de 2011}

El artículo presenta los resultados de la dimensión "Gobernabilidad y Ciudadanía" de una investigación más amplia denominada "Subjetividad Juvenil y Reproducción Social de la Democracia en Nicaragua” que realizó el Centro de Análisis Sociocultural de la Universidad Centroamericana (CASC-UCA). El estudio se basa principalmente en una encuesta realizada en octubre de 2010 a una muestra aleatoria de 1,145 jóvenes urbanos del área metropolitana de Managua. Entre los hallazgos de este estudio se puede mencionar que la juventud urbana es mayoritariamente portadora de valores democráticos como la tolerancia y el respeto mutuo entre ciudadanos en relación con la diversidad étnica y la equidad de género. La gran mayoría expresó su interés en participar en las elecciones presidenciales de 2011 porque lo consideran un derecho y/o un deber ciudadano, reflejando así una valoración positiva de la democracia electoral. El estudio ha detectado algunas contradicciones entre el discurso y la práctica de los/as jóvenes encuestados, lo que refleja un proceso dinámico y multifacético de conformación de la cultura política en esta etapa vital en que confluyen elementos de la cultura política autoritaria tradicional y nuevos aportes de una cultura democrática emergente.

Palabras clave: juventud urbana / cultura política / participación ciudadana

* Investigadora del Centro de Análisis Sociocultural, Universidad Centroamericana (CASC-UCA). Correo electrónico: hloreley1@yahoo.com

** Sociólogo, Investigador Asociado del CASC-UCA. Correo electrónico: luishectorserra@yahoo.com.ar 


\section{Introducción}

En este artículo presentamos los principales resultados sobre gobernabilidad y ciudadanía de la investigación titulada "Subjetividad Juvenil y Reproducción Social de la Democracia en Nicaragua”, que realizó el Centro de Análisis Sociocultural de la Universidad Centroamericana (CASC-UCA) en conjunto con la Facultad Latinoamericana de Ciencias Sociales (FLACSO), sede El Salvador. Este estudio se implementó en tres países de la región centroamericana (Nicaragua, El Salvador y Guatemala) con el apoyo financiero de la Agencia de Cooperación Internacional para el Desarrollo (AECI).

La investigación se propuso como objetivo responder a la siguiente interrogante: ¿Cuál es la subjetividad, la cultura política y los componentes de su reproducción en el grupo de jóvenes urbanos de 15-29 años de edad que constituyen la primera generación posterior al conflicto bélico en Nicaragua? El estudio se planteó identificar y analizar los componentes materiales y subjetivos de la reproducción social de la cultura política de los/as jóvenes urbanos del área metropolitana de Managua. Esto supuso superar la descripción de los elementos subjetivos de la cultura política y lograr un mayor nivel de construcción cognitiva, identificando tipologías de cultura política entre los jóvenes que sean expresión de diferentes elementos de la reproducción de la misma: pautas de percepción, de razonamiento, argumentación y comportamiento. En este sentido, la investigación pretende contribuir a una mejor comprensión de la cultura política de la juventud urbana del área metropolitana, de tal manera que los actores políticos, las organizaciones civiles y los ciudadanos puedan detectar las debilidades y las fortalezas para mejorar sus estrategias de acción con miras a fortalecer la democracia participativa.

\section{Marco conceptual}

El tema de la cultura política de la juventud ha sido relevante en las Ciencias Sociales, incluida la Ciencia Política, por cuanto es un componente clave en la dinámica del sistema político democrático y no democrático de una nación. No obstante, los estudios revelan un mayor interés en las percepciones y expectativas de la juventud, relegando la correlación entre los elementos subjetivos y dinámicos de la cultura política. Consideramos que para analizar el funcionamiento de las instituciones y de la participación ciudadana, debemos abordar la cultura política que portan los/as jóvenes, orientando sus percepciones políticas y conductas en un contexto histórico cambiante.

Tal como expone Zetino (2010), la cultura política debe considerarse como un conjunto de pautas dinámicas de representación de la realidad (modos de ver), de razonamiento (modos de entender), de argumentación (modos de explicar) y pautas de posicionamiento y comportamiento político (predisposiciones para el comportamiento y la acción política) de un determinado grupo. Estas pautas surgen de los conocimientos, creencias, emociones, sentimientos, consideraciones normativas y juicios valorativos que tienen como objeto, procesos sociales y fenómenos políticos. Los elementos subjetivos de la cultura política son las orientaciones psicosociales 
(cognitiva, emotiva y evaluativa); por el contrario, los elementos de la reproducción de la cultura política son las pautas.

Ahora bien, existen variables condicionantes de la subjetividad, tales como el posicionamiento estructural de los jóvenes en los ámbitos económicos, sociales, culturales y políticos, que está condicionado por el género, sexo, escolaridad, nacionalidad, estado civil, pertenencia religiosa y política, grupo étnico, y situación económica.

La definición de juventud en el estudio va más allá de su característica etaria. Tal como afirma Macedo (citado por Cerna Martínez, Doñas Castellanos, \& Durán Bonilla, 2006), conceptualizar la juventud implica necesariamente hablar de la construcción de una identidad. El concepto de juventud debe elaborarse como una categoría socio histórica y el análisis de la cultura política de los jóvenes debe contextualizarse en una sociedad y una época determinada.

Este estudio regional se concentró en los jóvenes urbanos de Nicaragua, Guatemala y El Salvador que tienen una edad entre 15 y 29 años. Buena parte de estos jóvenes vivieron conflictos político-militares en estos países y luego de los acuerdos de paz, han experimentado procesos democratizadores bajo regímenes neoliberales en el marco de un proceso de integración regional. Este colectivo de jóvenes representa un segmento de edad de mucha importancia en las dinámicas de integración social. Aquí se encuentran los jóvenes que están asumiendo plenos derechos y deberes cívicos, ingresando a los mercados laborales y tejiendo nuevas redes sociales tanto presenciales como virtuales. En definitiva es en este grupo de edad que se pretende estudiar la subjetividad juvenil asociada a la construcción del ideal democrático perseguido en las reformas políticas de la región.

Partimos del supuesto de que la reproducción social del orden democrático depende no sólo de la existencia del marco institucional y sus aparatos ideológicos dedicados a la difusión de las pautas de comportamiento ciudadano (Briones \& Ramos, 1995). Requiere también de una apropiación intergeneracional de valores y patrones de comportamiento frente a la vida personal, la convivencia social y la dinámica política. En este punto, el segmento juvenil es clave como actor de desarrollo y reproducción de las pautas, valores y actitudes acordes al orden democrático.

\section{Metodología}

El estudio es de carácter cuantitativo, transversal, descriptivo y analítico. Una de las técnicas de recopilación de información fue la investigación documental, que incluyó la revisión de estudios sobre juventud en general, así como investigaciones sobre cultura política juvenil en Nicaragua y sobre la región metropolitana de Managua.

El trabajo de campo consistió en la aplicación de una encuesta que abordó diversos temas: datos personales, medios de comunicación, relaciones sociales, visión del país, auto percepción, construcción de ciudadanía, visión regional, reflexiones finales y expectativas.

El universo en estudio fueron los jóvenes urbanos en edades de entre 15 y 29 años, de tres municipios del área metropolitana de Managua: Managua, Masaya y Granada, que suman 386,441 jóvenes (Instituto Nicaragüense de Información de Desarrollo [INIDE], 2007). Se eligió la capital por ser el área núcleo de la 
región metropolitana, la cual concentra el poder político y económico del país; los municipios de Masaya y Granada son zonas ligadas estrechamente a Managua por múltiples vínculos socioeconómicos y buenas vías de comunicación y transporte. Se diseñó una muestra probabilística que ascendió a 1,145 jóvenes de entre 15 y 29 años, de los cuales $41.0 \%$ eran jóvenes de Managua, 32.7\% de Masaya y 26.4\% de Granada. Por sexo fueron $48.6 \%$ hombres y $51.4 \%$ mujeres. Dicha muestra se calculó con un nivel de confianza del 95\% y un error muestral del $3.0 \%$ para toda la población joven de los tres municipios.

El método de muestreo utilizado fue aleatorio estratificado y aleatorio por conglomerado polietápico en cada estrato socioeconómico de cada municipio. Se consideraron tres estratificaciones: municipios (Managua, Masaya y Granada), edad (15-17 años, 18-24 años y 25-29 años) y el nivel socioeconómico según atributos indicativos de los barrios de residencia (estrato socioeconómico $1,2,3$ y 4) ${ }^{1}$, tal como aparece en el cuadro que sigue.

Cuadro 1. Muestra de jóvenes encuestados/as por municipio, edad y estrato socioeconómico (frecuencias)

\begin{tabular}{|c|c|c|c|c|}
\hline \multirow{2}{*}{ Municipios } & \multicolumn{4}{|c|}{ Edad en rangos } \\
\hline & 15-17 años & 18-24 años & 25- 29 años & Total \\
\hline Managua & 96 & 236 & 137 & 469 \\
\hline Masaya & 70 & 202 & 102 & 374 \\
\hline Granada & 52 & 168 & 82 & 302 \\
\hline Total & 218 & 606 & 321 & 1145 \\
\hline \multirow[b]{2}{*}{ Municipios } & \multicolumn{4}{|c|}{ Estratificación } \\
\hline & $\begin{array}{c}\text { Estrato } \\
\text { socioeconómico 1 }\end{array}$ & $\begin{array}{c}\text { Estrato } \\
\text { socioeconómico } 2\end{array}$ & $\begin{array}{c}\text { Estrato } \\
\text { socioeconómico } 3 \\
\end{array}$ & $\begin{array}{c}\text { Estrato } \\
\text { socioeconómico } 4 \\
\end{array}$ \\
\hline Managua & 38 & 357 & 45 & \begin{tabular}{|l}
29 \\
\end{tabular} \\
\hline Masaya & 31 & 327 & 0 & 16 \\
\hline Granada & 35 & 250 & 0 & 17 \\
\hline Total & 104 & 934 & 45 & 62 \\
\hline
\end{tabular}

El procedimiento para seleccionar las unidades muestrales constó de cuatro etapas. La unidad primaria de muestreo correspondió a las localidades según el estrato socioeconómico, las cuales se escogieron mediante muestreo aleatorio simple a través del programa Excel. La unidad secundaria de muestreo fueron las viviendas en las localidades seleccionadas. Se seleccionaron 10 viviendas en cada localidad de Managua, 16 viviendas en cada localidad de Masaya y 18 viviendas en cada localidad de Granada. Dicha selección se llevó a cabo usando el muestreo aleatorio sistemático y haciendo uso de los mapas cartográficos del Instituto Nicaragüense de Información de Desarrollo de 2005. La unidad terciaria de muestreo correspondió al hogar en

1 Se utilizó la clasificación de INIDE (2007). El estrato socioeconómico 1 estaba conformado por la lista de asentamientos que tenían 19.9\% o menos hogares no pobres; el estrato socioeconómico 2 estaba constituido por los barrios que tenían entre el 20.0\%-89.99\% de hogares no pobres; el estrato socioeconómico 3 estaba integrado por las residenciales que tenían entre 90.0\%-95.0\% de hogares no pobres y el Estrato socioeconómico 4 lo conformaron las residenciales que tenían de 95.01\%$100.0 \%$ de hogares no pobres. 
cada vivienda. El procedimiento de selección en las viviendas con dos o más hogares fue por muestreo aleatorio simple. La unidad última de muestreo fueron los jóvenes de 15-29 años que cumplían con el criterio de selección referido a la estratificación por edad. Si en el hogar había dos o más jóvenes que cumplían con la característica de selección, entonces se seleccionaba la persona cuya fecha de cumpleaños estuviera más próxima al momento del levantamiento de la información. En caso de que el joven con las características etarias no se encontraba en el hogar seleccionado, se buscaba en el otro hogar de la misma vivienda y de no ser posible, se utilizó como método de sustitución el de la vivienda siguiente.

La información de los cuestionarios fue digitada en el programa estadístico SPSS y el método de análisis de la información fue univariado y multivariado

\subsection{La región metropolitana de Managua}

El estudio se realizó en la región metropolitana de Managua (RMM) que está conformada por los departamentos de Managua, Masaya, Granada y Carazo, los cuales contienen en conjunto 30 municipios. Cuenta con una extensión territorial de $6,242.43 \mathrm{~km} 2$ que corresponde al 5\% de la superficie total del país, y una densidad poblacional de 216.9 habitantes por $\mathrm{km} 2$.

La RMM representa el 38,8\% del total de las actividades económicas del país y concentra la mayor parte del comercio y los servicios de la nación. En esta región se ubican los segmentos de población con mejor instrucción y con mayores recursos; el grueso de las actividades económicas y la población activa; así como las mayores inversiones industriales, comerciales y de servicios.

El producto interno bruto (PIB) de la RMM sumó 14.9 mil millones de córdobas (a precios constantes de 1994), concentrando 50.4\% del PIB total nacional (Alcaldía de Managua, 2007).

La RMM concentra también el poder político del país. Aquí está ubicado el centro político- administrativo de la nación. Se localiza el gobierno central, los ministerios de Gobierno, los poderes del Estado, los tribunales de apelaciones más importantes, las sedes de los partidos políticos.

Los gobiernos municipales de la RMM recaudan el 50\% de los recursos que recogen todos los municipios del país y tienen una estructura orgánica más completa.

\subsection{Caracterización de la muestra}

En este apartado se presentan las principales características socio-demográficas y los perfiles de subjetividad inicial.

\subsubsection{El perfil socio-demográfico de los jóvenes urbanos}

De los 1,145 jóvenes encuestados/as, un poco más de la mitad son mujeres y el resto son hombres. El promedio de edad fue de 21.67 años. Por tramos de edad, los/as jóvenes entre 18-24 años son el grupo mayoritario (52.9\%), seguido por los individuos con edad entre los 25-29 años (28.0\%) y 15-17 años de edad (19.0\%). 
Con relación al nivel educativo, el promedio de años escolares cursados es de casi cinco años (4.94). En términos globales, un 43.8\% de los/as jóvenes tiene un nivel de escolaridad de bachillerato incompleto y $18.9 \%$ completo. También hay un porcentaje importante de jóvenes que alcanzaron el nivel educativo de universitario incompleto o graduado (24.1\%).

Según la condición civil, existe un claro predominio de los/as solteros/as (6 de cada 10 personas) sobre los/as casados/as o acompañados/as. En el ámbito religioso, prevalecen los jóvenes que profesan alguna religión: 83.1\% son católicos/ as o evangélicos/as.

La vinculación laboral revela que el $59.7 \%$ son población económicamente activa dependiente (PEAD) y el $40.3 \%$ pertenecen a la población económicamente activa independiente (PEAI). La PEAD está compuesta por los jóvenes que se dedican sólo a estudiar (29.2\%), a los quehaceres de la casa (20.3\%) y los que se dedican a los quehaceres de la casa y a estudiar o los que están ociosos/as (suman 10.3\%). Por el contrario, la PEAI la conforman el $29.5 \%$ de los que se dedican sólo a trabajar y el $10.8 \%$ que hacen cualquiera de las siguientes combinaciones: trabajar y estudiar; a los quehaceres de la casa y a trabajar; a trabajar, estudiar y a los quehaceres de la casa.

Cabe resaltar que no se incluye como actividad laboral los quehaceres del hogar por no generar remuneración económica de forma explícita, aún cuando en la práctica esto representa una enorme contribución a la economía de los hogares.

Según la identidad subjetiva, el $74.1 \%$ de los/as jóvenes se auto perciben como jóvenes y el resto (25.9\%) dicen ser adultos. Al interior de quienes se consideran adultos, hay una leve predominancia de las mujeres respecto a los hombres $(28.7 \%$ y $22.9 \%$ respectivamente), lo que se explica porque las mujeres tienen que asumir obligaciones dentro del hogar a edades tempranas, responsabilidades que son propias del mundo de los adultos (ver cuadro 2).

Cuadro 2. Características generales de los/as jóvenes urbanos encuestados/as

\begin{tabular}{|lc|}
\hline Características generales & Porcentajes \\
\hline Sexo & \\
Hombre & 48.6 \\
Mujer $\quad$ Rangos de edad & 51.4 \\
15-17 años & \\
18-24 años & 19.0 \\
25-29 años & 52.9 \\
Promedio & 28.0 \\
Nivel educativo & 21.67 \\
Primaria incompleta & \\
Bachillerato incompleto & 9.4 \\
Bachillerato completo & 43.8 \\
Técnico incompleto & 18.9 \\
Técnico graduado & 2.4 \\
Universitario incompleto & 1.2 \\
\hline
\end{tabular}




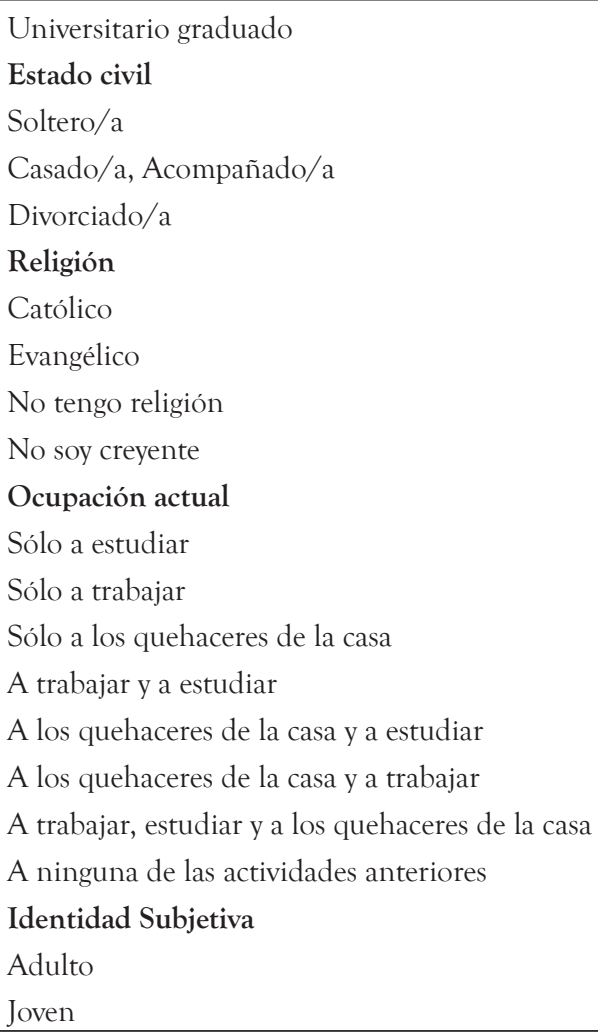

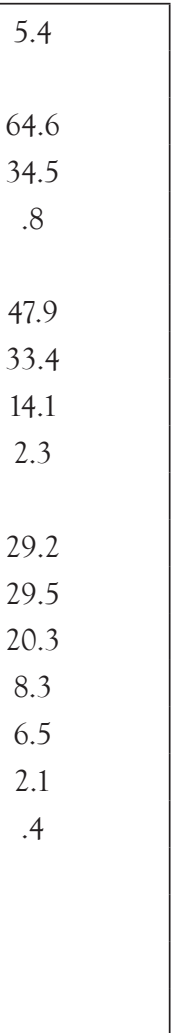

\subsubsection{Los perfiles de subjetividad inicial}

El estudio utilizó la técnica estadística de conglomerados o clústeres en el procesamiento de datos, tratando de agrupar la población encuestada según variables que reflejen una identificación subjetiva global y una predisposición de acción. Los perfiles no son tipos puros y no son excluyentes.

Para la construcción de los perfiles se optó por el método estadístico de conglomerados de K-medias, que permite el agrupamiento por similitud relacional de los casos. Se realizó una combinación simultánea de dos variables estructurales: PEA y edad, y una variable de subjetividad global, que consiste en su identificación con alguna de las siguientes posiciones ante la realidad social: la defensa de la tradición y el orden, buscar cambios políticos a favor de los pobres, impulsar la actividad empresarial, confiar en que Dios resolverá los problemas, vivir y dejar vivir, o ninguna de las opciones anteriores.

El resultado fueron cuatro perfiles: los reformistas tradicionales, los reformistas no tradicionales, los individualistas y los externalistas. Cómo se observa en el cuadro 3, la mayoría de la muestra corresponde al perfil de los individualistas (34.6\%), mientras que los porcentajes de los reformistas tradicionales, los reformistas no tradicionales y los externalistas, se acercan (20.0\%-25.2\%).

La caracterización de los perfiles a partir de las variables identificación, PEA y edad, es la que sigue: 
a. Reformistas tradicionales: son aquellos jóvenes que se identifican con la defensa de la tradición y el orden (50.3\%), pero que también buscan o aceptan cambios políticos a favor de los pobres (49.7\%). Se trata de jóvenes dependientes económicamente (84.7\%), con edades de 18-24 años (70.1\%) y en menor medida de $15-17$ años (29.9\%).

b. Reformistas no tradicionales: son aquellos jóvenes que principalmente se identifican con la búsqueda de cambios políticos a favor de los pobres (51.1\%), como segunda característica se identifican con quienes impulsan la actividad empresarial $(26.8 \%)$ y en tercera característica se identifican con quienes defienden la tradición y el orden (22.1\%). En otras palabras, son aquellos jóvenes que buscan cambios políticos, otorgando un papel importante en esos cambios al impulso de la actividad empresarial, pero dentro de los marcos de la tradición y el orden. Son típicamente jóvenes de PEA independiente (69.3\%), de edades entre los $25-29$ (68.0\%) y 18 24 años (32.0\%).

c. Individualistas: son aquellos jóvenes que reflejan una subjetividad que muestra un sentido de control interno e individual fuerte y de comportamiento típico de no comprometerse, que muestran rasgos claros del individualismo sociológico, económico y político. Son aquellos jóvenes que principalmente se identifican con la filosofía de vivir y dejar vivir sin asumir compromisos (67.7\%) o bien, con quienes confían en que Dios resolverá los problemas (32.3\%). La participación porcentual según población económicamente activa es relativamente similar (56.6\% independiente y $43.4 \%$ dependiente). Lo mismo ocurre con la distribución por edades: $58.6 \%$ tienen entre $18-24$ años y $41.4 \%$ presentan edades entre los 25- 29 años.

d. Externalistas: se propone esta denominación en oposición a la característica típica y central de "individualistas". Los externalistas reflejan una subjetividad cuyo énfasis central está en la ausencia de un sentido de control dentro de sí mismos (interno), localizándolo externamente. Es decir, depositan básicamente en una externalidad (agente social, fuerza económica o mágica) fuera de sus propias capacidades, la solución de los problemas y la dinámica de los procesos sociales. Son jóvenes que primeramente depositan su confianza en que Dios resolverá los problemas (48.7\%), o que otros factores externos como la actividad empresarial determina los procesos (20.9\%), o que por esa ausencia de sentido de control interno optan algunos de ellos en menor grado $(30.4 \%)$ por la filosofía de no comprometerse, vivir y dejar vivir. Son mayoritariamente PEA dependiente y con edades entre los 15-17 años (57.4\%) o 18-24 años (42.6\%). 
Cuadro 3. Perfiles de subjetividad global

\begin{tabular}{|c|c|c|c|c|}
\hline $\begin{array}{c}\text { Perfil de } \\
\text { subjetividad } \\
\text { global }\end{array}$ & Identificación & Edad & PEA & $\begin{array}{c}\text { Total de } \\
\text { casos }\end{array}$ \\
\hline $\begin{array}{l}\text { Reformistas } \\
\text { tradicionales }\end{array}$ & $\begin{array}{l}\text { Con quienes defienden } \\
\text { la tradición y el orden } \\
(50.3 \%) \\
\text { Con quienes buscan } \\
\text { cambios políticos a } \\
\text { favor de los pobres } \\
(49.7 \%)\end{array}$ & $\begin{array}{l}\text { 18-24 años }(70.1 \%) \\
15-17 \text { años }(29.9 \%)\end{array}$ & $\begin{array}{l}\text { Dependiente }(84.7 \%) \\
\text { Independiente }(15.3 \%)\end{array}$ & $\begin{array}{l}288 \\
(25.2 \%)\end{array}$ \\
\hline $\begin{array}{l}\text { Reformistas no } \\
\text { tradicionales }\end{array}$ & $\begin{array}{l}\text { Con quienes buscan } \\
\text { cambios políticos a } \\
\text { favor de los pobres } \\
(51.1 \%) \\
\text { Con quienes impulsan } \\
\text { la actividad empresarial } \\
(26.8 \%) \\
\text { Con quienes defienden } \\
\text { la tradición y el orden } \\
(22.1 \%)\end{array}$ & $\begin{array}{l}25-29 \text { años }(68.0 \%) \\
18-24 \text { años }(32.0 \%)\end{array}$ & $\begin{array}{l}\text { Independiente }(69.3 \%) \\
\text { Dependiente }(30.7 \%)\end{array}$ & $\begin{array}{l}231 \\
(20.2 \%)\end{array}$ \\
\hline Individualistas & $\begin{array}{l}\text { Con quienes viven, } \\
\text { dejan vivir y no se } \\
\text { comprometen }(67.7 \%) \text {. } \\
\text { Con quienes confían } \\
\text { en que Dios resolverá } \\
\text { los problemas }(32.3 \%)\end{array}$ & $\begin{array}{l}\text { 18-24 años }(58.6 \%) \\
25-29 \text { años }(41.4 \%)\end{array}$ & $\begin{array}{l}\text { Independiente (56.6\%) } \\
\text { Dependiente }(43.4 \%)\end{array}$ & $\begin{array}{l}396 \\
(34.6 \%)\end{array}$ \\
\hline Externalistas & $\begin{array}{l}\text { Con quienes confían } \\
\text { en que Dios resolverá } \\
\text { los problemas }(48.7 \%) \\
\text { Con quienes viven, } \\
\text { dejan vivir y no se } \\
\text { comprometen ( } 30.4 \%) \\
\text { Con quienes impulsan } \\
\text { la actividad empresarial } \\
(20.9 \%)\end{array}$ & $\begin{array}{l}15-17 \text { años }(57.4 \%) \\
18-24 \text { años (42.6\%) }\end{array}$ & $\begin{array}{l}\text { Dependiente }(85.2 \%) \\
\text { Independiente (14.8\%) }\end{array}$ & $\begin{array}{l}230 \\
(20.1 \%)\end{array}$ \\
\hline Total & & & & $\begin{array}{l}1,145.00 \\
(100.0 \%)\end{array}$ \\
\hline
\end{tabular}

\section{Principales hallazgos del estudio}

En este apartado se aborda: el acceso de la juventud a la información pública sobre la realidad nacional y mundial; el interés e identidad política de la juventud urbana; el ejercicio del sufragio; el asociacionismo de la juventud en organizaciones de distinto tipo; las percepciones de los/as jóvenes sobre el desempeño de las principales 
instituciones públicas y el nivel de confianza en sus líderes, tanto de entes estatales como organizaciones de la sociedad civil; el reconocimiento juvenil de los derechos y deberes civiles y políticos que posee la ciudadanía nicaragüense y el fenómeno de la inseguridad ciudadana.

\subsection{Información de la realidad nacional e internacional}

El $80.5 \%$ de los/as jóvenes urbanos afirman informarse sobre lo que sucede en el país y en el mundo. Un análisis por perfiles de subjetividad inicial reveló que son los reformistas no tradicionales y los individualistas los que más se informan $(90.3 \%$ y $81.9 \%$ respectivamente), en comparación con los reformistas tradicionales y los externalistas (ver ilustración 1).

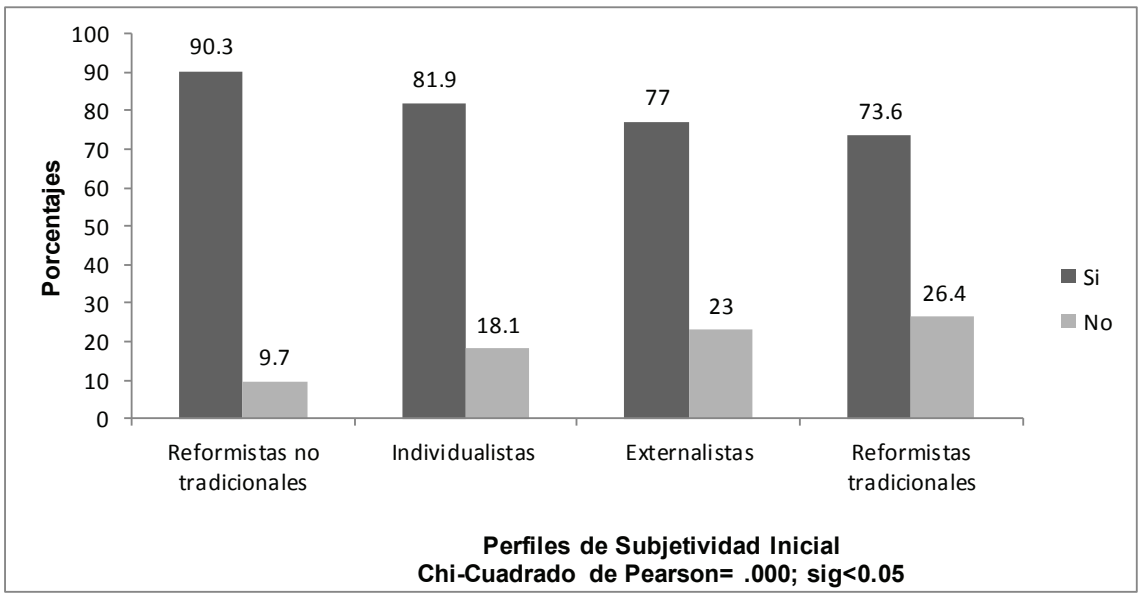

Ilustración 1. Jóvenes que se informan de lo que sucede según perfiles de subjetividad

Otras variables que explican la praxis de informarse sobre lo que sucede en el país y en el mundo son: la edad, la dependencia económica, la participación en organizaciones, el estado civil, el interés en la política y la categoría electoral. Los/ as jóvenes que se informan son, en su mayoría, del rango de edad más avanzado (2429 años), de la población económicamente activa independiente, de las personas que participan en organizaciones, que tienen mayor nivel de escolaridad, de los que están casado/acompañado/divorciado y de los/as que están más interesados/as en la política. También es mayor el interés para informarse de los electores votantes, seguido de los electores no votantes ${ }^{2}$.

Para los/as jóvenes que desean conocer lo que sucede en la realidad a nivel mundial y nacional, su principal fuente de información es la televisión nacional (74.8\%) que la mayoría mira todos los días, en segundo lugar se encuentra la

2 Los electores son personas mayores de 16 años de edad que tienen el derecho de elegir a sus representantes en el gobierno. Los no electores son aquellos que por ser menores de edad carecen de tal derecho. Dentro de los primeros, se puede hacer una distinción más; entre aquellos que en alguna ocasión han hecho uso de su condición de elector, a los que llamaremos electores votantes, y los que no, los identificaremos como los electores no votantes. 
familia y las amistades como canales de información cercanos $(50.5 \%$ y $48.8 \%$ respectivamente), en tercer lugar se ubican los periódicos (39.0\%) aunque la mayoría los leen al menos una vez a la semana, seguido de los/as que lo hacen todos los días (ver ilustración 2). El hecho de que entre las fuentes de información más utilizadas estén la televisión y el periódico, se explica porque estos medios tienen gran impacto a nivel urbano.

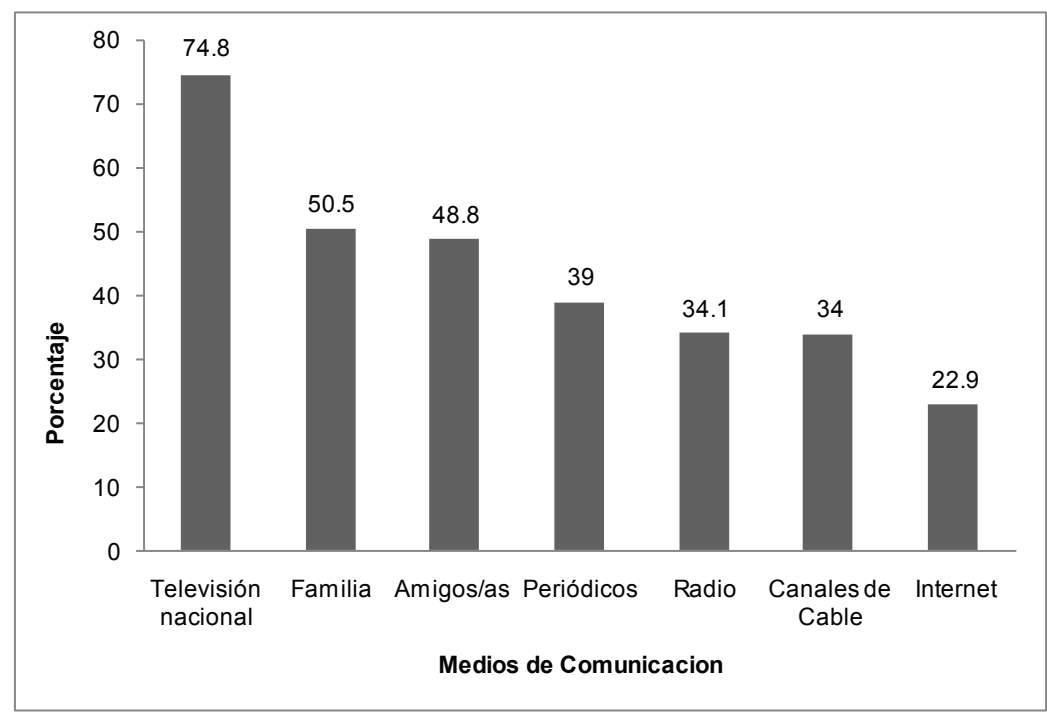

Ilustración 2. Fuentes de información utilizadas por los/as jóvenes

Los/as jóvenes encuestados/as consideran que los medios de comunicación que mejor (bastante o completamente) reflejan lo que pasa en la realidad de nuestro país y el mundo son la televisión nacional (67.5\%), los canales de cable $(51.7 \%)$ y la Internet (53.7\%).

Cuadro 4. Cuánto crees que los medios de comunicación reflejan lo que pasa en la realidad de nuestro país y del mundo

\begin{tabular}{|l|c|c|c|c|}
\hline Variable & Nada & Poco & Bastante & Completamente \\
\hline La Internet & 16.8 & 29.5 & 33.1 & 20.6 \\
\hline Canales de Cable & 14.2 & 34.0 & 40.4 & 11.3 \\
\hline Radio & 7.7 & 55.2 & 32.4 & 4.7 \\
\hline Periódicos & 5.4 & 54.1 & 35.1 & 5.5 \\
\hline Televisión nacional & 2.2 & 30.3 & 54.4 & 13.1 \\
\hline
\end{tabular}

Dentro de los temas que atraen más la atención de la juventud que se mantiene informada, se destacan los asuntos sociales, los espectáculos, la economía, los deportes y en menor medida los temas políticos, según muestra la ilustración 3. Por perfiles de subjetividad inicial, los individualistas y los reformistas no tradicionales son los que tienden a buscar más esa información ( $57.9 \%$ y $60.3 \%$ respectivamente). 


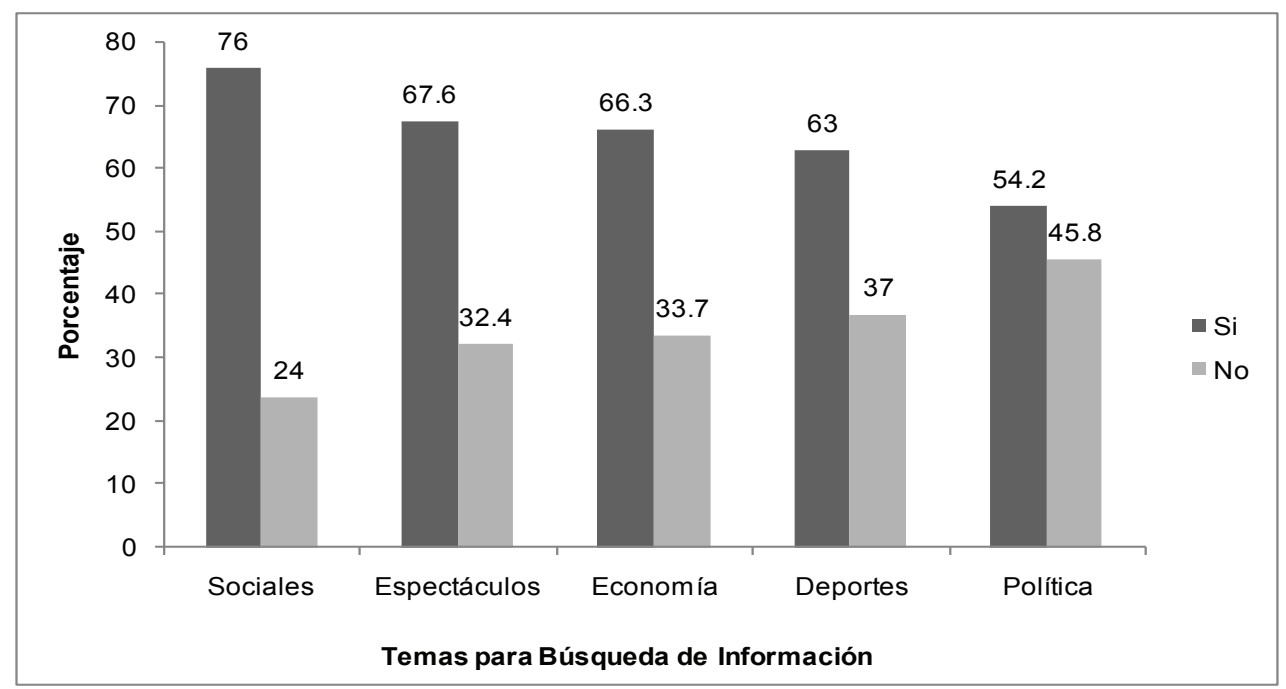

Ilustración 3. Temas o asuntos del país y del mundo sobre los que buscan información

\subsection{Interés e identidad política de la juventud urbana}

Sólo un $11.1 \%$ de los/as jóvenes está bastante o muy interesado en asuntos políticos, un tercio se mostró algo interesado y un 54\% no tiene ningún interés (ver ilustración 4). Quienes mayor interés tienen en la política son los/as jóvenes que se identifican ideológicamente con la izquierda política. Según los perfiles de subjetividad inicial, los que están menos interesados en la política son los reformistas tradicionales, los individualistas y los externalistas, en comparación con los reformistas no tradicionales.

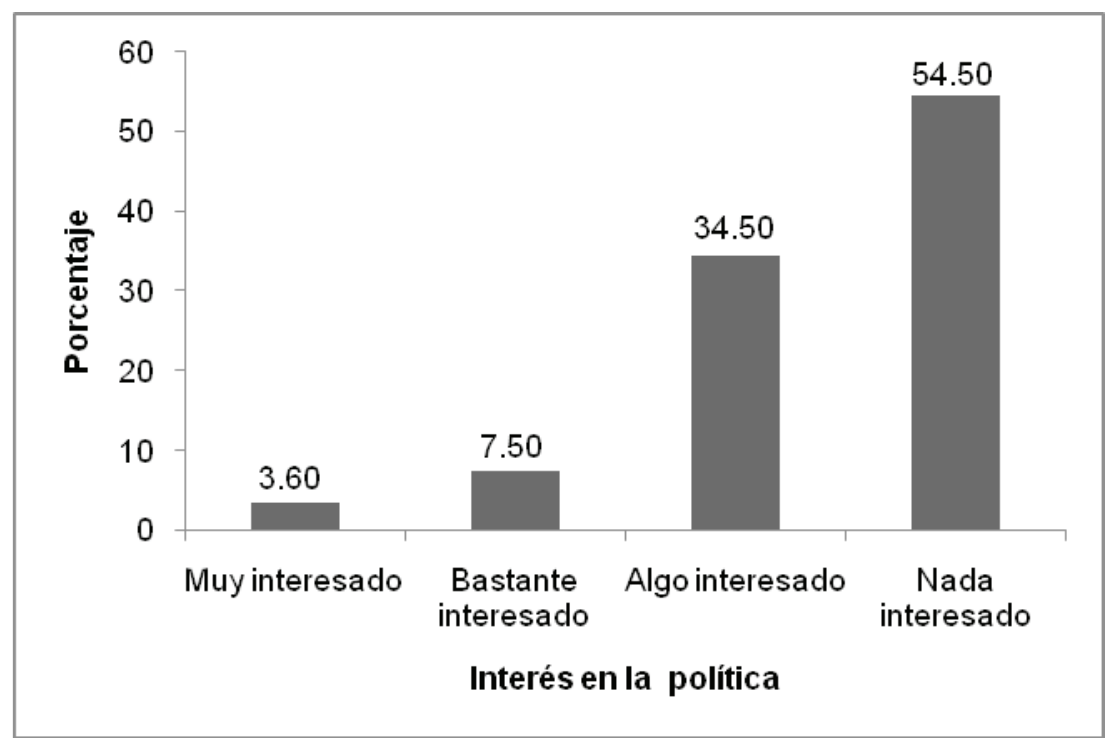

Ilustración 4. Interés en la política de las y los jóvenes encuestados 
Pese al bajo interés en la política, la mitad de los/as jóvenes (50.7\%) no están de acuerdo con que la política sea una actividad sólo de adultos, más aun, la gran mayoría $(92.8 \%)$ considera que los/as jóvenes pueden contribuir mucho para ayudar a resolver los problemas del país.

En cuanto a la identidad política, observamos un alto porcentaje que no sabe o no responde (27.9\%) lo cual expresa la dificultad de ubicarse en estas categorías tradicionales. Del 100\% de los que asumen una identidad política se ubican en primer lugar en el "centro" político: $40.7 \%$, en segundo lugar en la "derecha: $33.6 \%$ y en último lugar en la "izquierda": 25.7\% (ver cuadro 5).

Cuadro 5. Inclinación político-ideológica de la juventud urbana

\begin{tabular}{|l|c|c|}
\hline \multicolumn{1}{|c|}{ Variable } & Porcentaje & Porcentaje válido \\
\hline De derecha & 24.2 & 33.6 \\
\hline De centro & 29.3 & 40.7 \\
\hline De izquierda & 18.5 & 25.7 \\
\hline Total & 72.1 & 100.0 \\
\hline NS/NR & 27.9 & \\
\hline
\end{tabular}

\subsection{Ejercicio del sufragio}

Sólo la mitad de los/as jóvenes encuestados/as participaron en las elecciones municipales de 2008 porque consideran que es un derecho y/o un deber ciudadano (electores votantes). Por el contrario, el $51.3 \%$ de los jóvenes no participaron en esas elecciones. De éstos, el 37.6\% no lo hizo por ser menor de 16 años en 2008 (no elector), mientras que el restante $13.7 \%$ carecía de interés para ejercer el voto o de cédula de identidad, tal como ha sucedido en procesos electorales anteriores debido a las deficiencias del Consejo Supremo Electoral, institución responsable de otorgarla (Nevitte \& Serra, 2005). A esto se agrega que el $84.0 \%$ de los votantes y no votantes consideran que las elecciones más importantes son las presidenciales.

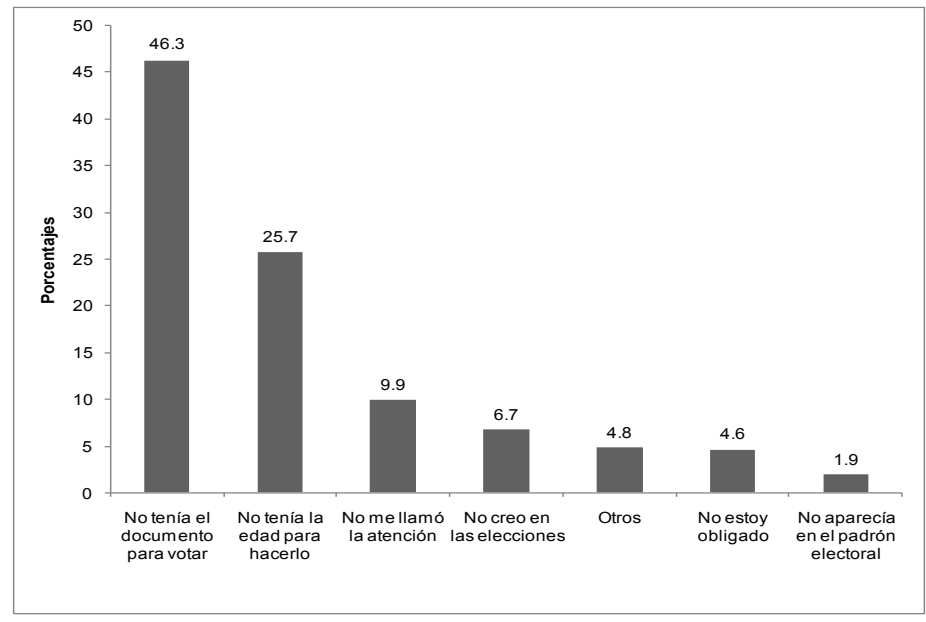

Ilustración 5. Razones de no haber votado en las elecciones municipales de 2008 
Un análisis del comportamiento electoral en los comicios del gobierno local según los perfiles de subjetividad inicial (exceptuando los no electores) revela que en orden jerárquico, son los reformistas no tradicionales y los individualistas (71.9\% y $57.6 \%)$ los que más practican el voto, lo cual se relaciona con la edad de estos grupos compuestos por jóvenes de entre 18-29 años quienes, en su mayoría, tienen su cedula de identidad y mayor interés en participar en elecciones (ver ilustración 6).

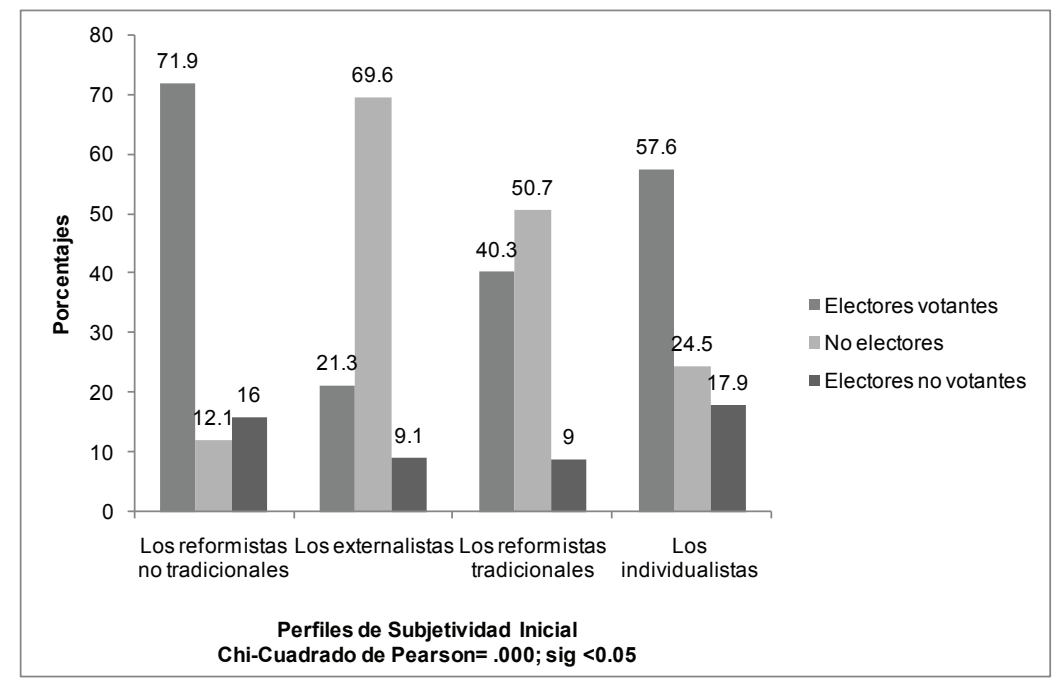

Ilustración 6. Categorías electorales según perfiles de subjetividad global

También encontramos que el sexo, la edad, el nivel educativo y la disposición para informarse de lo que sucede en el país y en el mundo funcionan como determinantes del voto. Hay mayor disposición de las mujeres (55.1\%) respecto a los hombres. Además, se comprueba la hipótesis de que, a medida que aumenta la edad, también hay mayor interés para votar: 50.0\% de los jóvenes con edades entre 18-24 años y $74.4 \%$ en las edades de $25-29$ años lo hacen.

La relación entre el nivel educativo y la praxis del voto indican que los que tienen un nivel educativo medio y superior $(56.8 \%$ y $35.7 \%$ ) son los que tienen un nivel más alto de votación. Además, las personas que optan por informarse de lo que sucede en el país y en el mundo representan la mayoría de los/as que votaron (53.1\%).

Respecto a la intención del voto en las elecciones presidenciales de noviembre de 2011, el 80.7\% manifestó que, de no tener ningún impedimento, ejercerían el sufragio porque lo consideran un derecho y/o un deber ciudadano. Cabe resaltar que según los perfiles de subjetividad inicial, los reformistas tradicionales y no tradicionales tienden en mayor proporción a ejercer el voto en esas elecciones (85.8\% y 87.4\%) en comparación con los individualistas o externalistas (un poco más de dos tercios). En términos generales, aquellos que están más comprometidos con los cambios, tendrían una mayor disposición a votar en las elecciones de 2011(ver ilustración 7). 


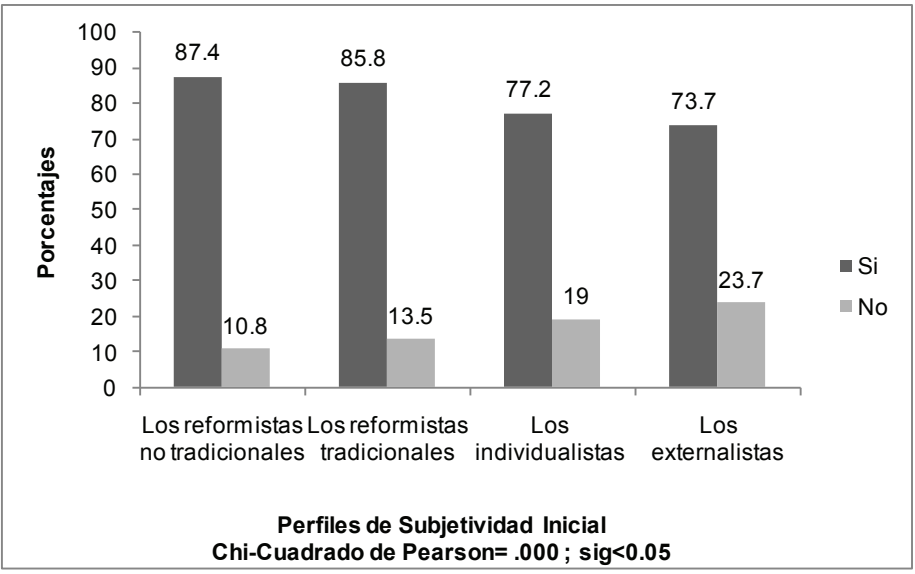

Ilustración 7. Disposición para votar en las elecciones de 2011 según perfiles de subjetividad

\section{4. Asociativismo Juvenil}

El 96.4\% de los/as jóvenes encuestados (96.4\%) expresaron que para resolver los problemas del país hay que estar organizado. Igualmente, un 95.7\% está de acuerdo que los jóvenes deben organizarse para defender sus derechos y un $88.6 \%$ considera que estas organizaciones deben ser dirigidas por jóvenes (ver ilustración 8).

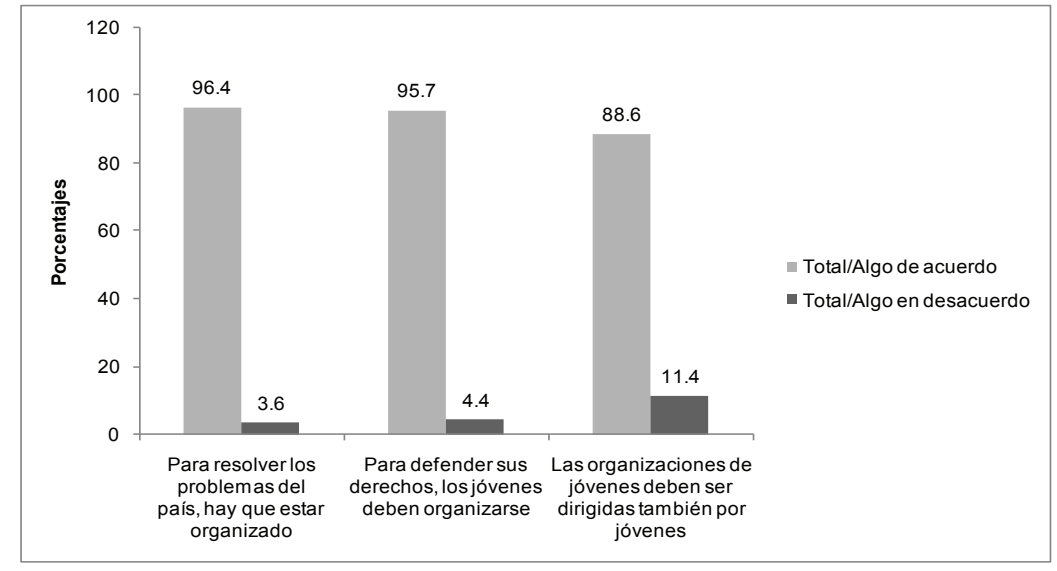

Ilustración 8. Valoración de la importancia de la asociatividad

Sin embargo, más de la mitad de los/as jóvenes no participan en ninguna organización principalmente por la falta de oportunidades para hacerlo y porque consideran que no trae beneficios o acarrea problemas. Por perfiles de subjetividad inicial se encontró que los reformistas no tradicionales, tradicionales y los externalistas son los que menos participan en organizaciones (48.5\% y $50.4 \%$ respectivamente), sin embargo expresaron su interés en hacerlo si tienen oportunidades, mientras que los individualistas (58.9\%) tienen posiciones más bien de rechazo a organizarse (ver cuadro 6). 
Cuadro 6. Razones de no participación en organizaciones según perfiles de subjetividad

\begin{tabular}{|c|c|c|c|c|c|c|}
\hline Variable & \multicolumn{4}{|c|}{ Perfiles de subjetividad inicial } & \multirow[b]{2}{*}{ Total } & \multirow[b]{2}{*}{$\mathrm{P}$} \\
\hline $\begin{array}{c}\text { Participación en } \\
\text { organizaciones }\end{array}$ & $\begin{array}{c}\text { Los reformistas } \\
\text { tradicionales }\end{array}$ & $\begin{array}{l}\text { Los reformistas } \\
\text { no tradicionales }\end{array}$ & $\begin{array}{c}\text { Los } \\
\text { individualistas }\end{array}$ & \begin{tabular}{|c|} 
Los \\
externalistas
\end{tabular} & & \\
\hline No participa & 53.5 & 48.5 & 60.9 & 50.4 & 54.4 & .009 \\
\hline \multicolumn{7}{|c|}{ Razón principal que has tenido para NO participar en ninguna organización. Opción 1} \\
\hline $\begin{array}{ll}\text { No he tenido la } \\
\text { oportunidad } \\
\text { hacerlo }\end{array}$ & 76.7 & 84.1 & 60.2 & 65.1 & 69.6 & \multirow{5}{*}{.000} \\
\hline $\begin{array}{l}\text { No se logra nada } \\
\text { de } \quad \text { provecho } \\
\text { organizándose } \\
\end{array}$ & 9.6 & 12.1 & 15.0 & 13.2 & 12.8 & \\
\hline Sólo trae problemas & 9.6 & 3.7 & 19.5 & 12.3 & 12.8 & \\
\hline $\begin{array}{l}\text { Para defender mis } \\
\text { derechos y mis ideas } \\
\text { es mejor hacerlo } \\
\text { solo }\end{array}$ & 4.1 & & 4.9 & 9.4 & 4.6 & \\
\hline Otros & & & .4 & & .2 & \\
\hline
\end{tabular}

En cuanto a la participación de la juventud en las organizaciones, se encontró que un $45.6 \%$ de los jóvenes del área metropolitana lo hacen. Las principales razones que los motivaron a participar en esas organizaciones han sido: "ser tomado en cuenta", "hacer amigos/as", "ayudar a otras personas" y "transformar ciertas cosas”. Las organizaciones en las cuales participan más los/as jóvenes encuestados son las iglesias (prácticamente 3 de cada 10 jóvenes), luego siguen las organizaciones recreativas (clubes deportivos, organizaciones culturales y artísticas) y los partidos políticos, donde participa 1 de cada 10 jóvenes (ver ilustración 9).

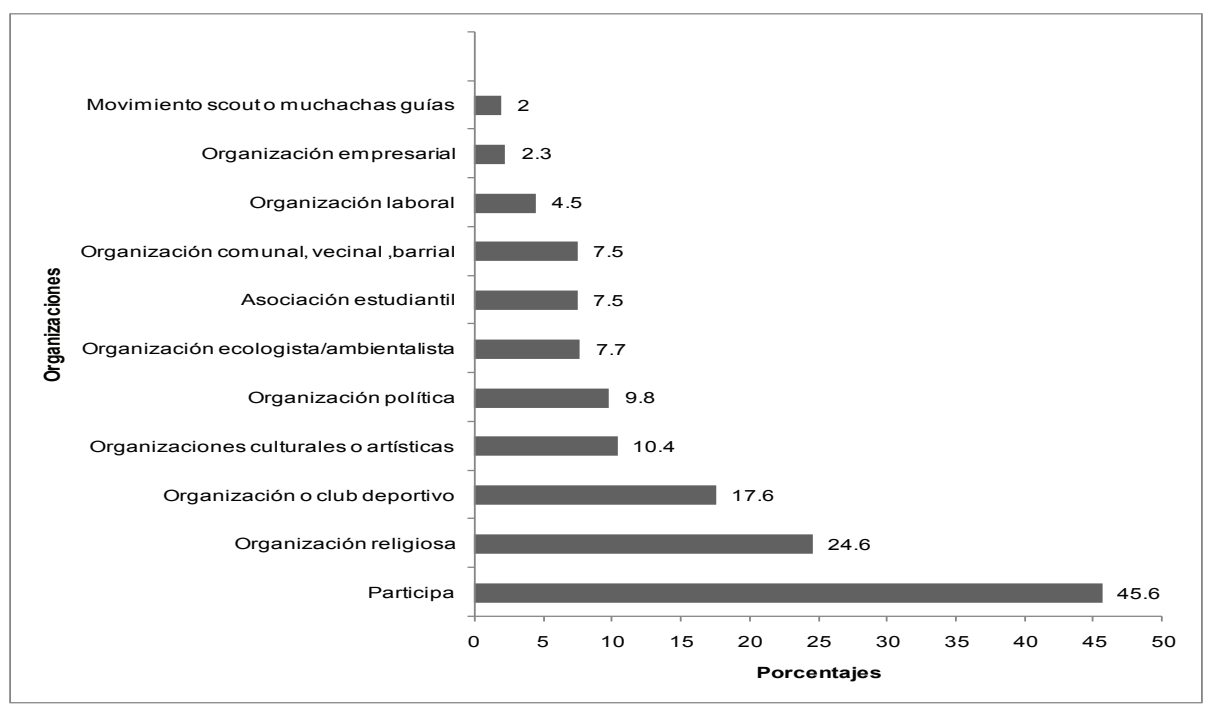

Ilustración 9. Participación juvenil en organizaciones 
Respecto al funcionamiento de las organizaciones, casi todos los/as encuestados/as (96.3\%) consideran que los/as miembros de una organización deben tener los mismos derechos, lo que expresa una concepción democrática y equitativa de la participación social.

Al preguntarles si alguna vez han participado en la toma de decisiones de esas organizaciones, la gran mayoría respondió afirmativamente. No obstante, la participación en decisiones de las organizaciones no es una demanda generalizada ya que el $65.2 \%$ de los/as jóvenes opina que son los dirigentes quienes deben tomar las decisiones. Tampoco reivindican el derecho que deben de tener los miembros/ as de las organizaciones en cuanto a la libertad de pensamiento y de expresar sus discrepancias, pues el 68.3\% de los/as jóvenes opinan que para que una organización funcione, es necesario que todos sus miembros piensen igual.

\subsection{Confianza en las instituciones y los funcionarios}

Entre los/as jóvenes urbanos predomina una desconfianza de las instituciones estatales, los funcionarios públicos y los políticos, a quienes perciben como personas interesadas en adquirir poder y beneficios económicos más que por solucionar los problemas del país. Los personajes públicos con mayor grado de desconfianza son los diputados, los dirigentes de partidos políticos, los ministros de gobierno y los sindicalistas.

Cuadro 7. Valoración sobre el desempeño de instituciones públicas

\begin{tabular}{|l|c|c|c|c|}
\hline Instituciones & Malo & Regular & Bueno & Excelente \\
\hline Partidos políticos & 37.1 & 52.3 & 9.0 & 1.6 \\
\hline Consejo Supremo Electoral & 32.6 & 46.6 & 17.6 & 3.2 \\
\hline Asamblea Legislativa & 24.6 & 62.6 & 11.3 & 1.5 \\
\hline Alcaldías & 19.5 & 50.6 & 26.8 & 3.1 \\
\hline Juzgados & 19.5 & 58.9 & 19.3 & 2.3 \\
\hline Gobierno & 19.0 & 57.7 & 17.8 & 5.4 \\
\hline Procuraduría General de la República & 18.8 & 59.5 & 18.7 & 3.0 \\
\hline Fiscalía & 18.3 & 61.4 & 18.2 & 2.2 \\
\hline Policía & 16.1 & 48.5 & 29.4 & 6.1 \\
\hline Procuraduría de Derechos Humanos & 12.3 & 41.6 & 36.6 & 9.5 \\
\hline Ejército & 12.7 & 46.9 & 34.4 & 6.0 \\
\hline Iglesias & 10.7 & 35.4 & 42.6 & 11.2 \\
\hline Medios de Comunicación & 7.7 & 42.9 & 39.3 & 10.1 \\
\hline
\end{tabular}

Un análisis de la confianza en los personajes públicos según perfiles de subjetividad inicial reveló significancia estadística en el caso de las preguntas referidas a la confianza en el alcalde/alcaldesa, dirigentes de partidos políticos, diputados, sindicalistas, militares, educadores, empresarios, jueces y policías. Los reformistas no tradicionales y los individualistas expresan mayores porcentajes de desaprobación de los diputados, alcalde/alcaldesa, empresarios y jueces. En el caso de los dirigentes de partidos políticos y los sindicalistas, son los individualistas y los externalistas los que 
mayor desconfianza tienen. Por el contrario, son los reformistas no tradicionales y los externalistas los que confían más en los educadores, los militares y los policías.

También son determinantes de la confianza de los/as jóvenes en los personajes públicos la ideología política, el sexo, el nivel educativo y la satisfacción con la vida. Existe mayor confianza de los que se identifican con la izquierda (probablemente simpatizantes del gobierno de turno); los hombres; los de mayor nivel educativo y mayor satisfacción personal con su vida.

\subsection{Desempeño de las instituciones}

Los/as jóvenes encuestados/as poseen una percepción negativa de la gestión realizada por los partidos políticos y los poderes Legislativo, Electoral y Ejecutivo (entre $89.4 \%$ y $77 \%$ ). También las instituciones del sector justicia y las alcaldías tienen porcentajes importantes de desaprobación. Por el contrario, se observa una percepción positiva de las iglesias, los medios de comunicación, la Procuraduría de Derechos Humanos, el Ejército y la Policía.

Especial interés tiene la valoración positiva de los medios de comunicación, la cual se refuerza al considerar que los medios cumplen un papel importante en la democratización del país (78.8\%), tienen libertad de expresión (74\%) y promueven el respeto y la tolerancia entre los ciudadanos (61.2\%).

Para ubicar las valoraciones de la juventud encuestada en su justa dimensión, es preciso recordar que pese al alto porcentaje de jóvenes $(80.5 \%$ ) que se informan periódicamente sobre la realidad nacional, únicamente el $54.2 \%$ busca información relacionada con la política. Además, al preguntarle a los/as jóvenes sobre qué tanto conocían sobre la labor de las instituciones públicas, relacionadas con los poderes legislativo, judicial y ejecutivo, se encontró que entre el $91.0 \%$ y el $94.2 \%$ conocían poco o nada.

El estudio del desempeño de las instituciones a partir de los perfiles de subjetividad inicial revela significancia estadística en el caso de los Juzgados, la Fiscalía, el Consejo Supremo Electoral, las Iglesias, el Ejército, la Policía y los Medios de comunicación. Los reformistas no tradicionales y los individualistas expresan una mayor desaprobación hacia los juzgados, la fiscalía y el Consejo Supremo Electoral, que los jóvenes de los otros perfiles. Por otro lado, son los reformistas no tradicionales y los externalistas los que confían más en la iglesia, medios de comunicación, la Policía y el Ejército. Se mantienen los otros determinantes de la confianza en los personajes públicos para el caso del desempeño de las instituciones.

\subsection{Derechos y deberes ciudadanos}

En este acápite presentamos los derechos y libertades civiles y los derechos políticos por cuanto son variables claves en los estudios de cultura política.

\subsubsection{Derechos y libertades civiles}

En general, la juventud urbana del área metropolitana muestra tolerancia frente al derecho ciudadano de libre expresión: 96.6\% está totalmente/ medianamente de 
acuerdo. Son los de mayor edad y los católicos y los que no tienen religión los que más aprueban la libre expresión.

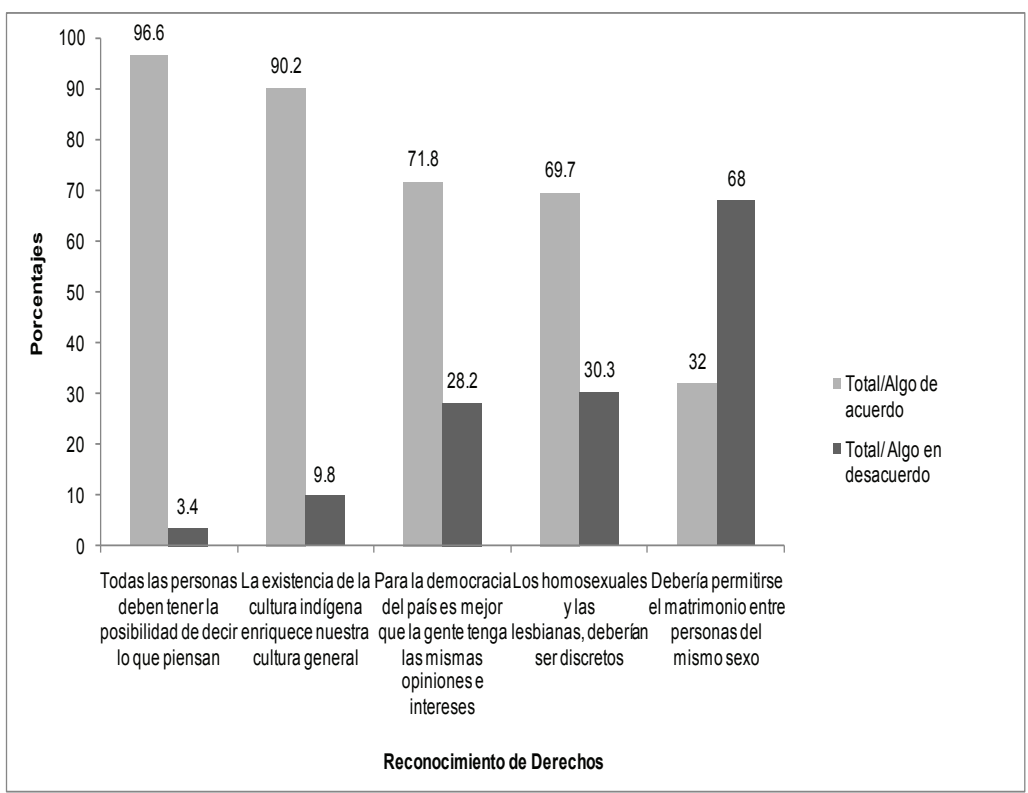

Ilustración 10. Reconocimiento de derechos civiles

Pese al reconocimiento unánime a la libertad de expresión, encontramos que más de dos tercios - principalmente los de menor edad- están de acuerdo con la idea de que es mejor que la gente tenga las mismas opiniones e intereses para que funcione la democracia. Se percibe una disociación entre democracia y pluralidad de opiniones e intereses. Con ello, según Ortega y Castillo (2006, p.55), "se estaría negando el derecho al disenso político, el cual es reconocido como un rasgo fundamental y positivo de las reglas del juego democráticas, ya que la oposición constituye el control indispensable de la acción del gobierno”.

Un análisis de la pregunta antes ilustrada según perfiles de subjetividad inicial, revela que son los reformistas tradicionales y no tradicionales $(77.2 \%$ y $74.1 \%$ respectivamente) los que mayoritariamente están de acuerdo con que el sistema democrático nicaragüense requiere que la ciudadanía tenga las mismas opiniones. Por el contrario, los individualistas y externalistas muestran una menor aprobación para que las personas tengan posiciones e intereses coincidentes $(70.0 \%$ y $65.9 \%$ respectivamente).

Con relación al derecho a la diversidad sexual, encontramos una tendencia mayoritaria a rechazar tal derecho. Más de dos tercios de los/as jóvenes encuestados/ as consideran que los homosexuales y lesbianas deben de ser discretos; y una misma proporción desaprueba el matrimonio entre personas del mismo sexo.

Según los perfiles de subjetividad inicial, los externalistas y los individualistas están en desacuerdo con el matrimonio entre personas del mismo sexo $(74.9 \%$ y $69.9 \%$ respectivamente) lo que puede deberse a la concentración de evangélicos que poseen esos grupos. Según el sexo, las mujeres son más tolerantes que los hombres 
respecto a la libre opción sexual, mientras que por religión, hay menos permisividad de los evangélicos y los que no tienen religión.

Con relación al derecho a la diversidad étnica, el 73.2\% de los/as jóvenes encuestados/as están totalmente de acuerdo con que la existencia de la cultura indígena enriquece nuestra cultura general.

Un indicador sobre los niveles de tolerancia y de respeto hacia grupos sociales discriminados se hizo a partir de la pregunta ¿votarías para presidente/a de la República por una mujer, una persona negra, una persona indígena, un homosexual o lesbiana? La mayoría de los jóvenes entrevistados tienen disposición para votar por una persona negra, una mujer y un indígena (entre $89.0 \%$ y $93.6 \%$ ), aunque menos votarían por un homosexual o lesbiana $(54.4 \%)$.

En relación a la equidad de género, más de dos tercios (73.7\%) consideran que las mujeres son tan capaces como los hombres para ocupar puestos de responsabilidad. El análisis de la interrogante antes planteada según perfiles de subjetividad inicial presenta significancia estadística para el caso de la votación por una persona negra, mujer e indígena. Son los reformistas no tradicionales los que muestran la mayor disposición para votar por esos actores, tal como muestra el cuadro 8.

Cuadro 8. Tolerancia al derecho de la postulación a cargos públicos según perfiles de subjetividad

\begin{tabular}{|c|c|c|c|c|c|c|}
\hline \multirow{2}{*}{$\begin{array}{c}\text { Votarías para } \\
\text { Presidente(a) de la } \\
\text { República por }\end{array}$} & \multicolumn{4}{|c|}{ Perfiles de subjetividad inicial } & \multirow[b]{2}{*}{ Total } & \multirow[b]{2}{*}{$\mathrm{P}$} \\
\hline & \begin{tabular}{|c|}
$\begin{array}{c}\text { Los reformistas } \\
\text { tradicionales }\end{array}$ \\
\end{tabular} & $\begin{array}{l}\text { Los reformistas } \\
\text { no tradicionales } \\
\end{array}$ & \begin{tabular}{|c|} 
Los \\
individualistas \\
\end{tabular} & \begin{tabular}{|c|} 
Los \\
externalistas \\
\end{tabular} & & \\
\hline \multicolumn{7}{|l|}{ Una persona negra } \\
\hline $\begin{array}{l}\text { Sí } \\
\text { No } \\
\end{array}$ & $\begin{array}{l}95.8 \\
4.2 \\
\end{array}$ & $\begin{array}{l}93.4 \\
6.6 \\
\end{array}$ & $\begin{array}{l}94.4 \\
5.6 \\
\end{array}$ & \begin{tabular}{|l|}
89.4 \\
10.6 \\
\end{tabular} & $\begin{array}{l}93.6 \\
6.4 \\
\end{array}$ & .024 \\
\hline \multicolumn{7}{|l|}{ Una mujer } \\
\hline $\begin{array}{l}\text { Sí } \\
\text { No }\end{array}$ & $\begin{array}{l}96.2 \\
3.8 \\
\end{array}$ & $\begin{array}{l}88.6 \\
11.4 \\
\end{array}$ & $\begin{array}{l}88.3 \\
11.7 \\
\end{array}$ & $\begin{array}{l}89.0 \\
11.0 \\
\end{array}$ & $\begin{array}{l}90.5 \\
9.5 \\
\end{array}$ & .002 \\
\hline \multicolumn{7}{|c|}{\begin{tabular}{ll|l} 
Una & persona \\
indígena & & \\
\end{tabular}} \\
\hline $\begin{array}{l}\text { Sí } \\
\text { No }\end{array}$ & $\begin{array}{l}91.6 \\
8.4 \\
\end{array}$ & $\begin{array}{l}91.7 \\
8.3 \\
\end{array}$ & $\begin{array}{l}88.9 \\
11.1\end{array}$ & $\begin{array}{l}83.0 \\
17.0\end{array}$ & $\begin{array}{l}89.0 \\
11.0 \\
\end{array}$ & .008 \\
\hline
\end{tabular}

\subsubsection{Derechos políticos}

Con relación a los derechos políticos, además del derecho al sufragio y a la libre expresión, ellos/as reconocen los siguientes derechos: recibir información sobre el desempeño de las autoridades (93.6\%), controlar el trabajo de las instituciones del gobierno (92.0\%), ayudar a resolver los problemas del país $(92.0 \%)$, participar en la política para cambiar el rumbo del país $(76.2 \%)$ y en menor medida, el derecho ciudadano de participar en la política (50.7\%), tal como muestra la ilustración 11. 


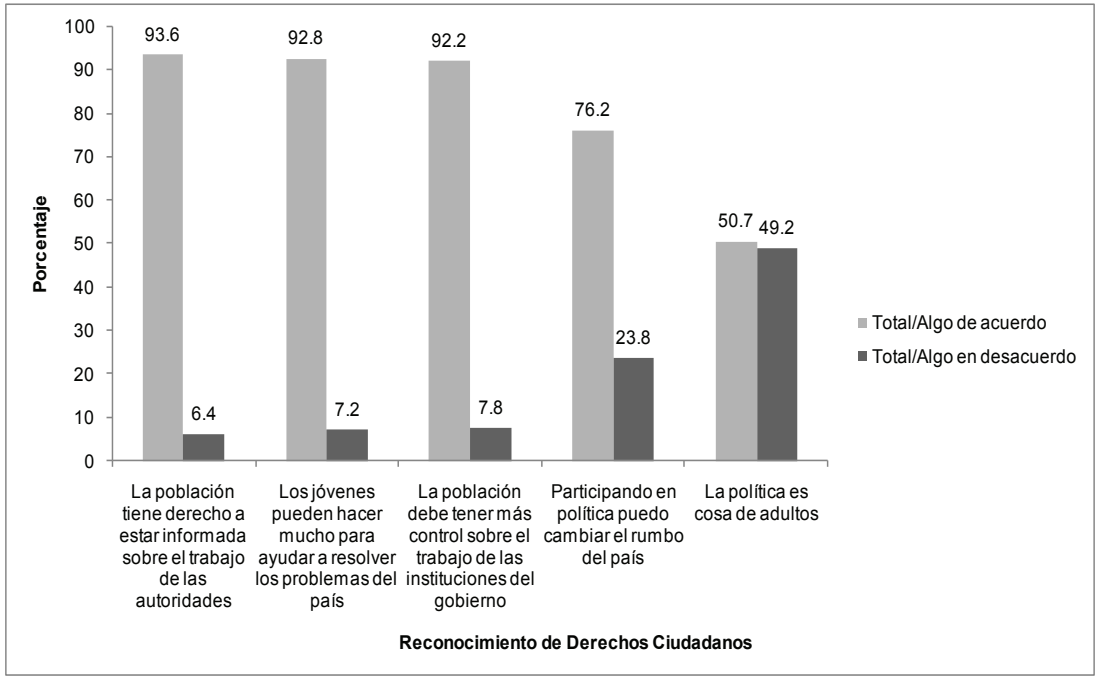

Ilustración 11. Reconocimiento de derechos ciudadanos

Los perfiles de subjetividad inicial muestran diferencias significativas al preguntarles sobre el derecho de "participar en la política para cambiar el rumbo del país”: los reformistas tradicionales y no tradicionales son los que mayoritariamente están de acuerdo, mientras que en cuanto al deber "ayudar a resolver los problemas del país”, son los reformistas no tradicionales y los externalistas los que alcanzan los mayores porcentajes de aprobación.

Un análisis del "derecho a participar en la política" según sexo, edad, nivel educativo e interés en la política, reveló que los hombres mayoritariamente lo reconocen; a medida que aumenta la edad, el nivel educativo y el interés en la política, también crece el reconocimiento a tales derechos. En el caso de la variable "los jóvenes pueden hacer mucho para ayudar a resolver los problemas del país", aparece una correlación positiva con el interés en la política.

Desde una perspectiva comparada con la generación de sus padres, un poco más de la mitad de los/as jóvenes entrevistados/as consideran que tienen mayores oportunidades para participar como ciudadano/a y para expresar sus opiniones, aunque un grupo significativo (un tercio) considera que la situación es igual que en el pasado, como muestra el cuadro 9.

Cuadro 9. Oportunidades de los/as jóvenes comparadas con sus padres

\begin{tabular}{|l|l|l|l|}
\hline Oportunidades & Peor & Igual & Mejor \\
\hline Participación como ciudadano & 16.5 & 33.0 & 50.5 \\
\hline Libertad de opinión y expresión & 13.9 & 23.3 & 62.8 \\
\hline
\end{tabular}

Por perfiles de subjetividad, los reformistas no tradicionales (60.5\%) consideran que ahora los jóvenes están mejor que sus padres respecto a la participación 
ciudadana, mientras que los reformistas tradicionales y los individualistas presentan porcentajes parecidos (49.0\%). Además, son los hombres jóvenes de mayor edad (2429 años) y los más interesados en la política, quienes consideran que la participación ciudadana del joven de hoy es mejor que la de sus padres.

La mayoría de los/as jóvenes encuestados/as están de acuerdo con acciones ciudadanas de carácter pacífico como expresarse a través de los medios de comunicación (89.9\%), marchar por las calles de la ciudad (74.9\%), reunirse en una plaza pública (73.5\%), u organizar paros y huelgas (61.7\%). Pero están en contra de acciones que afecten las propiedades públicas o privadas, tales como causar daños a un edificio o tomárselo para expresar sus demandas.

Para los/as jóvenes encuestados/as las características de un buen ciudadano son en orden jerárquico: ser respetuoso de las personas evitando problemas con los demás, ser cumplido con las leyes, velar por los derechos de todos/as, apoyar el desarrollo nacional y estar consciente de lo que sucede en el país (ilustración 12).

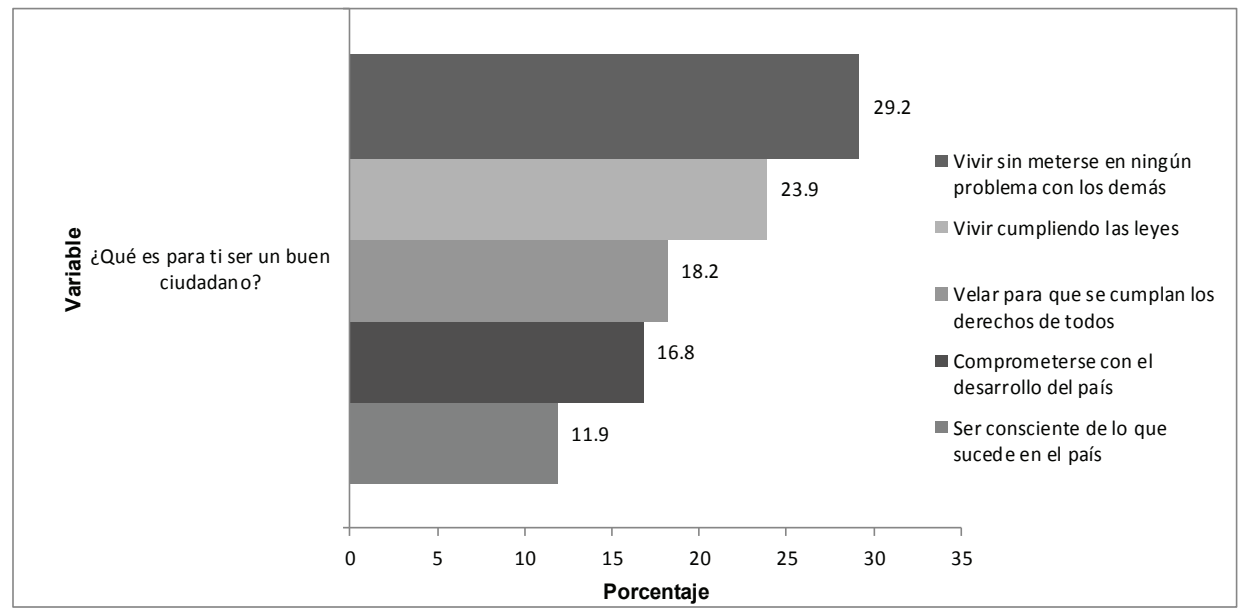

\subsection{Seguridad ciudadana}

La inseguridad y la violencia han sido reconocidas por los/as jóvenes entrevistados/ as como un problema que afecta a la sociedad nicaragüense, cuyas causas principales según el $60.1 \%$ son de origen institucional (falta de leyes fuertes, mal gobierno e inaplicabilidad de leyes existentes), o de orden social (39.0\%), las cuales están relacionadas con la pérdida de valores morales, falta de trabajo y educación y la deportación desde los Estados Unidos de migrantes con record delictivo. Estos datos contrastan con el informe de la segunda encuesta sobre percepción de seguridad ciudadana aplicada por el Instituto de Estudios Estratégicos y Políticas Públicas (2010, p.15), el cual reveló que "los factores que la ciudadanía considera están incrementando la violencia y la delincuencia en Nicaragua son: desempleo (65.6\%), consumo de drogas ilícitas $(18.6 \%)$ y en menor medida, el consumo de alcohol (7.5\%), poca presencia policial $(4.4 \%)$ e intolerancia política $(1.5 \%)$, entre otras”.

Al preguntar a los/as jóvenes si valoran que el gobierno está haciendo lo necesario para que las personas se sientan más seguras, un poco más de tres quintos 
de ellos/as (64.7\%) respondieron afirmativamente, lo cual se relaciona con la valoración positiva de la labor realizada por la Policía Nacional, aunque han habido denuncias contra esta institución pública por abusos de poder y por privilegiar los intereses del partido en el gobierno (Centro Nicaragüense de Derechos Humanos [CENIDH], 2009).

En términos comparativos generacionales, la mayoría de los/as jóvenes creen que la seguridad personal está igual o peor (71.0\%) que en la generación de sus padres, mientras que el $28.9 \%$ opina que ha mejorado (ver ilustración 13 ).

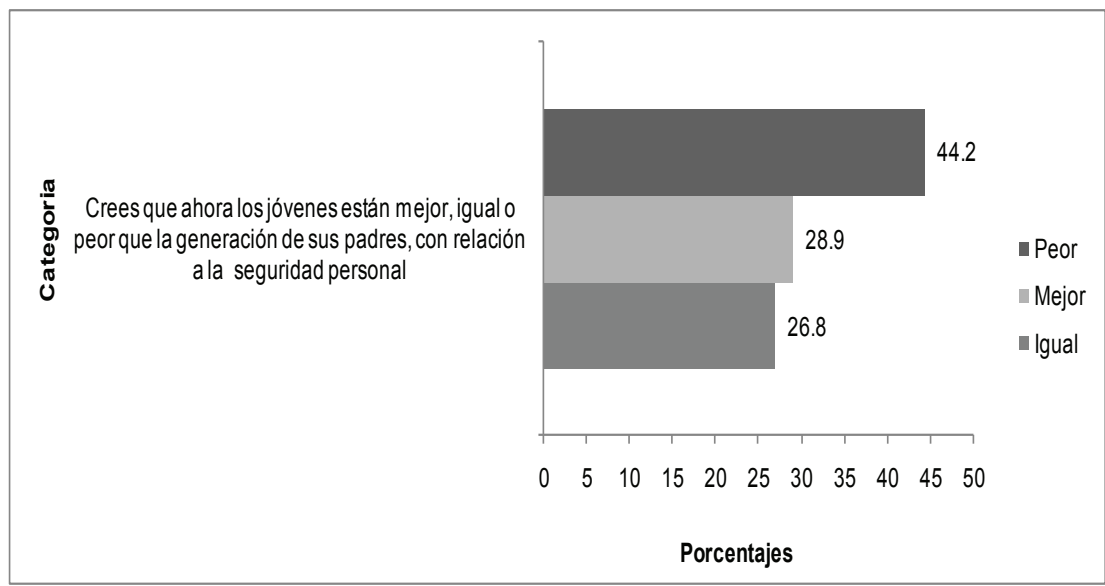

Ilustración 13. Valoración juvenil de la seguridad personal comparada con la generación de sus padres

Para enfrentar el problema de la violencia y la delincuencia, los/as jóvenes prefieren medidas preventivas, seguidas de acciones de control. En este sentido, el 95.2\% planteó que la solución consiste en la organización de los/as ciudadanos/as para prevenir el delito. También están de acuerdo con que se aprueben sanciones más duras (87.3\%), que la policía actúe con rudeza con los malhechores $(81.0 \%)$, que los menores de edad que delinquen sean castigados como adultos (61.6\%). Sin embargo, la mayoría de los/as jóvenes no está de acuerdo en que los ciudadanos hagan justicia por su propia mano, tampoco que se implante la pena de muerte en Nicaragua (70.4 y $63.1 \%$ respectivamente).

Con relación a la propuesta que el Ejército se encargue de la seguridad pública, el 61.9\% está de acuerdo. Sin embargo, la mayoría (70.8\%) está en contra de que los militares gobiernen el país, lo que xpresa su preferencia por la subordinación militar al poder civil establecido en la Constitución Política y el temor a una dictadura militar como en el pasado.

Por otro lado, una mayoría de jóvenes urbanos del área metropolitana está de acuerdo con que sólo Dios puede resolver esos problemas, lo que expresa una posición pasiva y dependiente de fuerzas supra humanas que minimiza las acciones políticas y sociales antes mencionadas. 


\section{Conclusiones}

Entre los hallazgos más relevantes de este estudio encontramos que la mayoría de los/as jóvenes de los municipios de Managua, Masaya y Granada se mantienen informados sobre lo que sucede en el país y en el mundo, básicamente a través de la televisión nacional, la familia y las amistades. Los temas políticos ocupan un lugar secundario ya que gran parte de los/las jóvenes no tienen interés en las actividades políticas y reconocen que saben muy poco sobre el quehacer de los poderes del Estado.

Casi la mitad de los/as jóvenes del área metropolitana participan en alguna organización religiosa, deportiva, cultural o política, por distintos motivos tales como hacer amigos/as, ayudar a otras personas y transformar la realidad. Esta participación en organizaciones sociales es un elemento clave en la construcción de capital social y de una ciudadanía protagónica en la mitad de la juventud urbana.

Por el contrario, la otra mitad de los/as jóvenes no participa en ninguna organización por la falta de oportunidades, la carencia de incentivos y las restricciones impuestas por la familia, particularmente a las mujeres. Sin embargo, todos/as los/ as jóvenes encuestados/as opinaron que para resolver los problemas del país hay que estar organizado y que los jóvenes deben organizarse para defender sus derechos.

En cuanto a la participación de la juventud en las últimas elecciones municipales (2008), no votaron quienes tenían menos de 16 años en esa fecha y tampoco lo hicieron muchos que carecían de la cédula de identidad o desconfiaban de las instituciones electorales. No obstante, la gran mayoría expresó su interés en participar en las elecciones presidenciales del 2011 porque lo consideran un derecho y/o un deber ciudadano, reflejando así una valoración positiva de la democracia electoral.

La juventud urbana es mayoritariamente portadora de valores democráticos como la tolerancia y el respeto mutuo entre ciudadanos/as en relación con la diversidad étnica y de género. Por otro lado, un sector de jóvenes expresaron su desaprobación a tener amistad con personas de otra ideología política u opción sexual, o que usen tatuajes o argollas en el cuerpo, lo cual indica la reproducción social de prejuicios y actitudes intolerantes en la joven generación.

Dos tercios de los/as jóvenes consideran que las mujeres son tan capaces como los hombres para ocupar puestos de responsabilidad, sin embargo el tercio restante reproduce la discriminación de género propia de la tradición patriarcal en Nicaragua.

La juventud urbana identifica claramente cuáles son los principales derechos civiles y políticos que tienen los/las ciudadanos/as en Nicaragua y los/as jóvenes consideran que hoy día ellos/as tienen mayores oportunidades para participar como ciudadanos/as y para expresar sus opiniones que la generación de sus padres.

En este estudio regional dirigido por FLACSO El Salvador se han elaborado perfiles o tipos de cultura política juvenil en Centroamérica para ayudarnos a comprender las diversas posiciones existentes según su identificación subjetiva y su predisposición de acción: 
- Los individualistas: Es el grupo con mayor población juvenil en Nicaragua conformado por los/as jóvenes que reflejan una subjetividad individual fuerte, poseen una visión pesimista del futuro, se identifican con la filosofía de vivir y dejar vivir, sin asumir compromisos de acción, ni participar en organizaciones sociales o políticas, aunque manifiestan interés en informarse sobre asuntos políticos y participar en elecciones.

- Los reformistas tradicionales: Constituyen el segundo grupo más numeroso compuesto por los/as jóvenes que se identifican con la defensa de la tradición y el orden, aunque aceptan participar en la política para realizar cambios a favor de los pobres y poseen una visión optimista del futuro.

- Los reformistas no tradicionales: Son aquellos/as jóvenes que buscan cambios políticos dentro del marco legal, participan en elecciones y otorgan un rol importante al sector empresarial. Por su tamaño, representan el tercer grupo más importante de la muestra.

- Los externalistas: Es el grupo más reducido y está compuesto por jóvenes de entre 15 y 24 años que esperan que los actores externos resuelvan los problemas del país, sea por intervención de Dios o de los gremios empresariales.

Este estudio ha detectado algunas contradicciones entre el discurso y la práctica de los/as jóvenes encuestados que reflejan un proceso dinámico y multifacético de conformación de la cultura política en esta etapa vital donde confluyen elementos de la cultura política autoritaria tradicional y nuevos aportes de una cultura democrática emergente.

Ya señalamos la divergencia entre la valoración de la organización social y la baja participación real de los/as jóvenes en alguna organización, salvo de carácter religioso. Así mismo, se ha observado en los/as jóvenes urbanos la reproducción de mitos tradicionales sobre la juventud, por ejemplo ser un grupo social irresponsable que provoca diversos problemas sociales.

También se nota, por un lado, un reconocimiento unánime a la libertad de expresión ciudadana que supone una diversidad de opiniones, y por otro lado, la idea de que es mejor que la gente tenga las mismas opiniones e intereses para que funcione la democracia, lo cual desvaloriza la diversidad de opiniones y el derecho ciudadano a disentir que enriquece el funcionamiento de un régimen democrático.

Hay que destacar que la mayoría de los/as jóvenes se sienten satisfechos con su vida y tienen una visión optimista del futuro personal y del país, a pesar de la problemática que afecta a la juventud urbana de los sectores populares. Los/ as jóvenes tienen la esperanza de que estos problemas se superarán en el futuro y están dispuestos a colaborar en su resolución, lo cual abre oportunidades para la participación de la juventud en la construcción de la democracia y el desarrollo de Nicaragua. 


\section{Referencias bibliográficas}

Alcaldía de Managua. (2007). Plan de Acción para la Región Metropolitana: Departamentos de Managua, Masaya, Granada y Carazo. Managua: Autor.

Briones, C. \& Ramos, C. (1995). Gobernabilidad en Centroamérica: Gobernabilidad, Economía y Democracia en El Salvador. San Salvador: FLACSO El Salvador.

Centro Nicaragüense de Derechos Humanos. (2009). Derechos humanos en Nicaragua. Managua: Autor.

Cerna Martínez, C., Doñas Castellanos, O. \& Durán Bonilla, J. (2006). Informe Regional Cultura Juvenil. San Salvador: Compañía de Jesús Provincia Centroamericana Sector Educativo.

Instituto de Estudios Estratégicos y Políticas Públicas. (2010). II Encuesta sobre Percepción de Seguridad Ciudadana. Managua: Autor.

Instituto Nicaragüense de Información de Desarrollo. (2007). Proyecciones 2007. Managua: Autor.

Nevitte, N. \& Serra, L. (2005). Democracia y Cultura Política en Nicaragua. Managua: Ética y Transparencia - Universidad Centroamericana.

Ortega, M. \& Castillo, M. (2006). Cultura Politica de la Democracia en Nicaragua: 2006. Managua: Vanderbilt University.

Zetino, M. (2010). Propuesta General de Construcción Analitica: Estudio sobre Subjetividad Juvenil y Reproducción Social de la Democracia en Centroamérica. San Salvador: FLACSO El Salvador. 